\title{
Corporate identity on the Web: The case of telecommunication companies in Ghana
}

\author{
Alimsiwen Elijah Ayaawan \\ Assistant Lecturer \\ Language Centre \\ University of Ghana, Legon, Ghana \\ E-mail: aayaawan@ug.edu.gh; alimsayaawan@gmail.com
}

Submitted: August 24, 2017 / Accepted: March 26, 2018 / Published: June 8, 2018

\begin{abstract}
The corporate website is an official communication medium for the construction of corporate identity. This study explores an important feature of corporate websites, the About Us section, within the framework of Critical Discourse Analysis (CDA) to establish how corporate identities are constructed, the discursive strategies used in constructing those identities and how ideology, hegemony and power inform the corporate identities and the discursive strategies used in enacting the identities. Data for the study are from the websites of the four leading telecommunication service providers in Ghana. The study has established that a glocalised corporate identity that is informed by Eurocentric capitalist ideology is constructed by the companies. The discursive strategies employed in enacting identity include the inverted pyramid structure of the narratives, interdiscursivity and binarity. It was also found out that the ideology that underpins the identities constructed created a power fluidity that resulted in hegemonic paradox.
\end{abstract}

Keywords: corporate identity, Critical Discourse Analysis, glocalisation, ideology, telecommunication companies

\section{Introduction}

The interest in the study of identity, especially with regard to how identity is constructed through discourse, has become integral to critical inquiries and research in a number of disciplines in the arts and social sciences. The consequence of this myriad of multidisciplinary interest in identity is that quite a generous number of perspectives have been adopted in examining this phenomenon. Amongst these approaches is the discourse analytic approach. A discourse analytic approach to identity is fruitful in that, as Hall (1992) stresses, discourse is essentially a group of statements that 
constitute a way of representing. An analysis of a discourse therefore offers an opportunity to examine how identity is constructed and enacted.

This study is interested in examining what has been referred to in the literature as corporate identity (Liu \& $\mathrm{Wu}$, 2015; Balmer, 2001; Stuart, 1999). Balmer (2001) has pointed to the multidisciplinary interest in the study of corporate identity. He argues that there is a 'cross-fertilization taking place among various literatures' (p. 249) when it comes to interest in the study of corporate identity. This cross-fertilisation is consensus gentium ${ }^{1}$ of the fact that the use of multidisciplinary approaches in examining the phenomenon will result in a more holistic examination. This is vital because of the recognition that identity, in general, and corporate identity, in particular, are important to organisations. Corporate identity is important to organisations because, as defined by Balmer (2001), it is 'the way in which an organisation's identity is revealed through behaviour, communications as well as through symbolism to internal and external audiences' (p. 241). A corporate identity is therefore the self-image which an organisation enacts itself for its audience. The corporate identity is vital for the existence of the organisation because the identity constructed defines the fundamental basis of the interaction that goes on between the corporate body and the individuals for which it exists and serves.

Corporate identity as a concept is viewed as 'a multifaceted conceptualisation of an organisation's structure, roles and values' (Evangelisti-Allori \& Garzone, 2010, p.12). This implies that knowing an organisation, especially in terms of what it stands for stems from an understanding of its corporate identity. The entire organisation, particularly in terms of its agenda, is defined by its corporate identity. The corporate identity therefore provides a stable platform from which the organisation projects itself and relates to others and also allows others to relate to it. Identity is crucial because, as Moingeon and Ramanantsoa (1997) argue, 'to know the identity of a person is to be able to identify him or her to distinguish him or her from others and to recognise him or her

1 a point of consensus and general acceptance

Legon Journal of the Humanities 29.1 (2018)

Page $\mid 74$ 
as a unique individual' (p. 283). As a corollary, in a competitive environment such as the telecommunication industry in Ghana, the need for the creation of unique corporate individuals becomes a matter of survival for the corporate entities involved. These unique corporate identities can be enacted discursively.

Another perspective on corporate identity is provided by Larçon and Reitter (1979), as cited in Balmer (2001). They present corporate identity as a 'set of interdependent characteristics of the organization that give it specificity, stability, and coherence' ( $p$. 291). Encapsulated in this definition of corporate identity is the foregrounding of the functional dimension to corporate identity. This is to say that Larcon and Reitter's definition of identity is hinged on the function to which identity can be used to perform within the context of the business and corporate world. The implication of highlighting the functional dimension of corporate identity (its specificity, stability and coherence ascribing nature) is that in the discursive construction of identity, entities adopt narrative strategies that are anchored on these attributes. This line of reasoning as reflected in Larcon and Reitter's definition of corporate identity is hard to dispute. This is because their reasoning recognises that what is intrinsic to the concept of identity is the idea of stability. An identity must be stable so that it forms the foundation for predictable values as well as predictable action (Burke \& Stets, 2009). In examining the discursive construction of identity in a given narrative therefore, one must pay critical attention to the nature of the image which is appropriated to create the stable identity for the entity involved.

Another important area that this study relates to is the nature of empirical studies that have been conducted on corporate identity. Liu and $\mathrm{Wu}$ (2015) have pointed out that the study of corporate identity has been facilitated by a number of genres, chiefly amongst these being promotional discourses within the corporate world. Other genres that have been used to bring the discourse analytic perspective to bear on corporate identity include financial reporting and organisational communication. 
Although the genres mentioned so far are all expected, in the sense they are traditionally the genres associated with the corporate world, there have been some studies which examined this phenomenon in the light of more modern and recent genres. Amongst these is a study conducted by Coupland (2002). Coupland's study examined how a socially responsible identity is constituted on a corporate website. Examining corporate identity as it is enacted through web sites is a fertile endeavour, given the fact that websites are one of the most important points of contact between individuals and other entities and corporate organisations (Park \& Reber, 2008).

Further, Coupland (2002) draws important parallels between such genres as mission statements and letters to shareholders on the one hand and corporate websites on the other. He notes that corporate websites are an important arena of official communication. The implication therefore is that corporate websites are a significant medium through which organisations officially provide information to targeted audiences. But perhaps, the most salient remark that Coupland makes within the context of this study is that corporate websites present a 'manufactured image available for interpretation' (p. 2). The image manufactured through the website is meant to construct a certain favourable identity for the organisation. One cannot but view the corporate website as an 'arena for the construction and display of identity' (p. 2). In consequence of this, it becomes important that we examine the strategies that are used in this medium to construct as well as enact corporate identities.

One feature that makes an examination of strategies for constructing corporate identities an intriguing and worthwhile endeavor is the fact that corporate websites have an audience with diverse interests. This diversity of interest means that corporate websites have come to be used as a medium for cultivating and maintaining relationships between corporate bodies and the public as a whole. A study by Park and Reber (2008) on Fortune 500 companies' use of websites revealed that these corporate bodies employ dialogic features in their websites to build as well as maintain relationships between the companies and their varied 
audience. Enclosed in the dialogic features of the websites are web resource addresses that house varieties of information appealing to different sections of their large audiences. This feature is made possible by the nature of the medium itself - the website. Suffice it mention that websites do not constitute the single medium for the construction of corporate identity on the Web. Ruellea and Peverelli (2016) note in a study on the discursive construction of identity that social media sites have become an essential forum for the construction of group identity broadly and corporate identity in particular. This study is also interested in the corporate website, but its focus is not on the entirety of the resources found on websites. Rather, the study examines the About Us section of the websites. The focus here stems from the observation that this section of the websites is the platform that is used to present a narrative about the corporate body of interest. The interest therefore is to examine how this feature is used discursively to construct and enact an identity for the company. This focus will again allow for a critical look at the kinds of strategies that are used in constructing and enacting these corporate identities.

\section{Exploring the niche}

Research into the use of the web to construct identities discursively is not new. For instance, Liu and Wu (2015) have examined the discursive construction of corporate identity from a glocalisation perspective. Their study examined the discursive construction of corporate identity on the web by 10 energy companies operating in China and the US. The work revealed that the companies employed both global and local patterns in constructing their corporate identities. Coupland (2002) also used discourse analysis to examine the construction of a socially responsible corporate identity on the web. His study presents the argument that a socially responsible identity is constructed though a language of morality. For their part, Park and Reber (2008) undertook a study that looked at how corporate bodies use the Web to both establish and maintain relationships between themselves and the public. What these studies have all demonstrated is that new 
insights into the construction of corporate identities can be gained when we investigate the websites of corporate bodies. This study intends to contribute to our understanding of corporate identities as they are constructed on the web. In spite of the fact that this study is similar to the studies that have been cited above, it is important to state clearly that it is in no way a replication. This study's focus is on the strategies that are used in constructing identities on the websites of corporate bodies and it also examines how ideology, hegemony and power inform the construction of corporate identity. Another justification for this study is that, a review of the literature on corporate identity construction on the web reveals the dearth of studies that have looked at this area in relation to companies in Ghana. The study therefore examines the construction of corporate identities by corporate bodies in Ghana on the web so as to draw attention to how the peculiarities of the socio-cultural environment in this part of the world may influence the corporate identities constructed.

\section{Research questions}

This study is guided by the following research questions:

I. What identities are constructed in the About Us section of corporate websites?

2. What strategies are used to discursively construct corporate identities in the About Us section of corporate websites?

3. How do ideology, hegemony and power inform the discursive construction of corporate identity?

\section{Methodology}

\section{Data}

The data for this study comprise the About Us sections extracted from four telecommunication companies operating in Ghana. The four companies are MTN Ghana, Vodafone Ghana, Millicom Ghana (Tigo) and Airtel Ghana. According to the information on Ghana's National Communications Authority's website, there are six (6) telecommunication companies operating 
in Ghana as of February 2017. Out of this number, only two (2) were excluded from this study. Two criteria were used in selecting the companies from which data were derived for this study. The first criterion was network coverage. The study decided to cover those telecommunication companies that had nationwide coverage. This is because to establish how the socio-cultural context of Ghana impacted the corporate identities being constructed through these websites, it is important for the company to be aware that it is addressing the entirety of Ghana and this awareness would be guaranteed if a company has nationwide coverage. The second criterion used in deciding the data source was the market share of the telecommunication companies in terms of both voice and data subscription. A high number of subscribers means that the companies concerned have a large target audience to communicate with through their respective websites. This awareness again will have an influence on the kinds of identities that are constructed on the websites. Statistics from the National Communications Authority as of February 2017 indicate that for voice and data subscription, MTN had $51.65 \%$ and $57.26 \%$ respectively; Vodafone's stood at $21.48 \%$ and $12.97 \%$ respectively; Tigo, $13.15 \%$ and $13.83 \%$ respectively; and Airtel $11.54 \%$ and $14.43 \%$ respectively. These four (4) telecommunication companies therefore accounted for close to $98 \%$ for both voice and data subscriptions in Ghana, with Expresso and Glo Mobile accounting for the remaining 2\%. It was also revealed that both Expresso and Glo do not have nationwide coverage. In the light of the set criteria for selection and in consideration of the facts retrieved from the National Communications Authority's website, the decision was made to restrict the data sources to MTN, Vodafone, Airtel and Tigo.

\section{Processing of data}

The About Us section which is housed within the homepages of the websites of the companies mentioned above was extracted from the sites and saved as a word document. Each About $U_{S}$ is a narrative averaging 100 words in length. The narratives generally give a description of each company and outline their mission and 
the vision statements. The data, now in Microsoft Word format were then used in the analysis. For MTN, Tigo and Vodafone, there were no hyperlinks embedded in the narratives. These were therefore straightforward when it came to converting them to the Word formats. However, for Airtel, it was realised that hyperlinks were embedded in the About Us section. These links served as deictic markers and directed visitors to specific information about the company. The researcher therefore had to retrieve the information embedded in each of these hyperlinks in so far as it relates to the narrative of the About Us.

\section{Framework of analysis}

The study employed a Critical Discourse Analysis (CDA) framework. CDA, according to Wodak (1996), is an approach to discourse analysis that highlights the substantively linguistic and discursive nature of social relations of power in contemporary societies. At the locus of critical discourse analysis is what Wodak and Meyer (2008) term the critical impetus. This critical impetus is focused on bringing to light the interconnectedness of phenomena The assumption is that within every form of discourse are embedded meanings and beliefs that do not overtly make themselves manifest and can only be revealed by the process of critical enquiry. The need to pay attention to the interconnectedness of phenomena within the framework of CDA is fed by a far more fundamental and wholly-accepted assumption - that language, which finds expression in discourse, is essentially social practice. This fundamental assumption becomes the premise for arguing that the social norms, beliefs and conventions of a given social structure shape the language in use and as such, the language in use cannot but reflect and express the beliefs, norms and conventions of that socio-cultural context and structure. This is not to say that language being a social practice means that it is a mere mirror of social structure. Wodak and Meyer (2008) point to the dialectical relationship between language (discourse) and society. Language does not just reflect and reinforce social conventions, it also serves as the axiom of social change and transformation. 
The implication of this framework of analysis then is that it allows the study to transcend a mere description of the social practice - the About Us discursive practice - by providing a lens through which to examine how the identities are constructed and how the strategies used in constructing such identities express the symbiotic relationship between social structure and language as social practice. Further, van Dijk (2008) has argued that CDA moves beyond the relationship between discourse and social structure to evaluate general social representations of values, norms, attitudes, ideologies and knowledge. This makes CDA a suitable framework for examining the latent meanings that lie beneath identities that have been discursively constructed by the telecommunication companies in the narratives. For, it is argued that values, norms attitudes, ideologies and knowledge constitute the building blocks of any given identity. These then, when expressed in language will come to constitute the identity of the subject of a piece of discourse. A further advantage afforded by CDA is that it provides a framework for a study of the narratives (text) within context. This reflects the generally accepted notion of discourse as a social practice since social practice is action within a given context. To understand how identity is constructed in the text means to understand the social context of the narrative of the About $U s$ section.

Two other concepts are woven into the fabric and the practice of CDA and have implications for this study. These are power and ideology. The concepts of power and ideology have dictated the choice of analytical framework. According to Wodak and Meyer (2008), critique, which arguably is the defining element of CDA, 'regularly aims at revealing structures of power and unmasking ideologies' (p. 8). Ideology is a 'coherent and relatively stable set of beliefs or values' (p. 8) whilst power, in the view of Weber (1980), cited in Wodak and Meyer (2008) is 'the chance that an individual in a social relationship can achieve his or her own will even against the resistance of others' (p. 28). From the explanations of both power and ideology given above, it can be argued that identity is a function of these two concepts in the sense that they define and constrain the kind of identity that is constructed by an individual, and in this 
case, an entity. The set of stable beliefs and the estimation of what can be achieved in spite of resistance become the fulcrum of an identity. Within the context of this study therefore, CDA is used to investigate how power and ideology define the identity constructed by these telecommunication companies and how the identities give expression to power and ideology.

\section{Common anchors of corporate identity of telecommunication companies in Ghana}

Telecommunication companies in Ghana, which are at the center of the enquiry into corporate identities and how they are constructed, employ a common discursive strategy which serves as the structuring framework for the construction of their individual identities. This framework resembles an inverted pyramid. This inverted pyramid is not identical with the concept as found in journalistic writing where the focus is on the hierarchical arrangement of information to reflect relative importance (Thompson, White \& Kitley, 2008). Rather, within this inverted pyramid on corporate websites, we find that the companies first construct a broad globalised/ international identity which effectively serves as the foundation, an important credibility fulcrum around which the more localised identities of the companies are then constructed. These localised identities arise from the immediate social structure within which the companies exist. This strategy results in the construction of a glocalised identity (Liu \& Wu, 2015) which ties the company to the two cultural contexts within which it exists. What is at the apex of this strategy for identity construction is a narrative that indicates the extent to which the specific company is woven into the fabric of a larger and more global entity. For Vodafone-Ghana for instance, the opening of the discourse about the company makes clear that it is 'an operating company of Vodafone Group Plc' and goes on to add that this company exists in other places such as Europe, the Middle East, Africa, Asia Pacific and the United States.

The length to which the discourse goes to situate the entire identity of companies on their status as global entities indicates that there is premium in this image. By highlighting their presence 
Ayaawan, A. E./ Legon Journal of the Humanities 29.1 (2018) around the corners of the globe, the companies succeed in building an image of success not only in providing services to markets more advanced than the Ghanaian one but as having had an important hand in the creation of the First World conditions that exist in these places, the Global North. This finding departs from the conclusions made by Liu and $\mathrm{Wu}$ (2015) that multi-national corporations operating in China demonstrate 'local preferences in ethical identity construction' (p. 58). This strategy therefore implicitly implies that the presence of the company within the socio-economic context of Ghana will lead to the creation of such conditions in the country. This strategy - hinging and subsuming the corporate identity on a more global entity - appears to be a strong image marketing strategy given the argument that people in the developing world in general hold the view that international corporations and anything that originates in the West have greater worth and have greater credibility.

The strategy that has been adopted and as described above, can be envisioned to succeed in presenting a credible corporate identity to audiences. Seen in this light, the identity that is being constructed by Ghana's major telecommunication companies is informed by a Eurocentric ideology. Within this Eurocentric ideology is a schema (van Dijk, 1998) of first world-third world which confers credibility on the First World and as such, allows the identity to be constructed around this schema which then facilitates the appropriation of its most important feature - credibility. Further, by constructing an identity that is rooted within this schema, the discourse allows itself to be shaped by this ideology. Therefore, it can be concluded that the discursive construction of corporate identity here is an instance of how discourse reproduces social domination and gives legitimacy to an established ideology instead of challenging and confronting that ideology (Wodak \&Meyer, 2008; Billig, 2003).

In spite of the above arguments, the strategy adopted also has implications that may result in the construction of a negative self-image. By highlighting the foreign roots of a company, the narrative also underscores the position that the company has a 
culturally and socially inorganic relationship with the society that is now its host. Highlighting the non-Ghanaian identity and hence the foreign identity of the companies creates a socially distal relationship between the companies and their immediate social structure. This approach to the construction of the corporate identities results, to an extent, in the construction of a self-image that foregrounds the profit-making aspect of these companies. This tangent to the narrative of self-constructed identity by the companies has the propensity of negating other attempts within the same narrative to conceal the here-for-profit aspect of the identities of these telecommunication companies.

A last word on the pyramidic structure, which is used as the strategy to shape the narrative about self, will focus on what corresponds to the tip of the pyramid. From the data, it is observed that the narrative concludes by tying the entity to a well-defined set of goals and objectives. These goals and objectives characterise the companies in that they legitimise their existence by ascribing to them a defined sense of purpose. The objectives that are projected here are those that position the company as the provider of what is needed by the consumer. This strategy allows the corporate body to shift the narrative from itself onto its target market, thereby creating the impression that it is its market, the individual consumer of its products, that is its focus. By simultaneously making itself peripheral and the consumer central in the discursive enactment of its own identity, it succeeds in concealing its true purpose as a profit-centred entity. It is also telling that this significant shift in the narrative occurs at the tip of the pyramid. This is because it helps create the impression that all that is contained within the body of the inverted pyramid is a rudimentary stage in an evolutionary process ending in the finished article at the tip of the inverted pyramid. In other words, the structure of the narratives helps create the impression that the entire narrative, prior to the point where the objectives have been stated, is a foundation for the flourish at the end. The real intent of the narrative is the positioning of the individual and his or her needs as the objective of the entity, the reason for which the entity exists. This therefore helps in constructing an identity of 
individual centeredness for the company whilst hiding its overall objective as a profit-making company.

\section{Heterogeneity of the corporate identity of Ghana's telecommunication companies}

Despite the impression of homogeneity of identity that has so far been created as a result of the focus on the generality in terms of the discursive strategy for the construction of corporate identity, it will be eons from the truth to argue that the four (4) telecommunication companies in Ghana that are the focus of this investigation have a homogeneous identity. The analysis from this point onwards will therefore turn its focus to the individual corporate identities that have been constructed through the narratives on these companies' websites.

Regarding MTN, perhaps, the most important feature of its corporate identity and manner in which that identity is constructed is the enacting of a binarity that allows the company to create a horizontal relationship with Ghana, its market. This binarity allows the discourse to forge an equivalence between MTN and Ghana which in turn establishes the context for the company to position itself as an equal partner in 'Ghana's economic growth and development'. By creating this equivalence and horizontal relationship, the capitalist intentions that gave birth to and continually shape the actions of the company are masked. What is presented through the narrative is an entity whose interest is not profit-making but one whose focus is the facilitation of the development of Ghana. Even the provision of telecommunications services, which is the primary objective of the company and as such is at the centre of its identity, is subsumed within its constructed identity as a partner in development. This is what is clearly implied when the narrative points out that 'creating sustainable corporate social investment initiatives' is at the core of its mission. The narrative therefore succeeds in linking the corporate identity of the company to the wider narrative of development championed by different Ghanaian governments and international agencies whose true interests are not in the making of profits. 
The strategy adopted therefore is interdiscursive - for as Bhatia (2010) points out, interdiscursivity essentially is the "function of appropriation of generic resources, primarily contextual in nature, focusing on specific relationships between and across discursive and professional practices as well as professional cultures' (p. 33). What is found within the narrative is an appropriation of the discourse of development, specifically its lexicogrammar. This appropriation, it must be argued, is driven by an awareness of the greater visibility of the discourse of development as well as its positive themes within the socio-cultural context of Ghana. The interdiscursivity is therefore employed here to persuasively confer credibility on the identity being constructed for the company.

On the surface, it will therefore appear that the discourse in this instance is de-hegemonic since the relationship is horizontal. It is not. For, within the context of the binarity, the company presents itself as the agency that will bring about the economic development that the country needs. This essentially is an expression of power, the ability to bring about socio-economic transformation, which results in the construction of a hegemonic relationship between the company and Ghana, the social structure within which its identity is constructed. Hegemony, as Simon (1982) succinctly defines, is the 'organisation of consent' (p. 21). This consent allows for a dominance that does not rise out of force but out of ideology; where ideology is understood as 'the process through which the dominant ideas within a given society reflect the interests of a ruling economic class' (Stoddart, 2007, p. 192). Within the concept of globalisation which constitutes the overall context of the discourse, the economic ruling class is the West. It is the West that authors the narrative of development and creates the dialectic of First versus Third Worlds. This dialectic is at the core of the ideology that is appropriated within the discourse to create the hegemonic relationship between MTN-Ghana and its market, Ghana.

Therefore, in spite of the use of the principle of binarity to create equivalence between Ghana and MTN, the narrative still succeeds in ensuring that the identities of the two entities 
are not dialectically opposed but complementary. It creates this complementary identity by means of a strong metaphor - the vehicle. Ghana in terms of physical identity is a space that is static, motionless and settled. MTN is projected as a vehicle full of motion, movement and an instrument of freedom. The vehicle goes where the individual owner drives it to. To the individual customers then, the identity of MTN is that of a company whose purpose is to afford subjects the means to do whatever it is they desire to undertake. By creating an intrinsic relationship between itself and agency, the company succeeds in making itself appealing to the individual. This image is further reinforced when the narrative states that the company is the vehicle that ferries customers to a 'bold, new Digital World'. The company is therefore presented as a benevolent organisation that enhances the existence of the individual by introducing him/her to that which is critical to their self-improvement - 'a new Digital World'. Although it is the case that the company enacts a servile identity for itself to create the impression that the individual customer is the one in the position of power, the reverse is what is achieved. This seeming paradox is what Wodak and Meyer (2008) draws attention to when they argue that 'suggesting how happy people will become if they buy specific consumer products is also an exercise of power; marketing provides us with a large body of knowledge of powerful techniques' (p. 9).

Another angle from which the principle of binarity is used to construct contrasting yet complementary identities to create a strong corporate identity for MTN is that of growth, especially in the economic sense. The narrative presents Ghana as an entity in need of economic growth. Ghana is therefore ascribed with an identity that positions her as young, evolving and in need of help. This general characterisation allows the individual who is the actual customer of MTN to see himself/herself as someone who needs growth and improvement. That help can only be provided by an entity that is economically mature. For this reason, MTN is presented as mature in the sense that it is ready to provide what is needed for the growth and development of Ghana. The narrative therefore presents the company as an accomplished company that is 
itself the finished product, ready to help the country climb the ladder of economic growth and maturity. The contrasting identities created for the two entities - Ghana and MTN - by means of this approach do have implications in regard to the nature of the social distance between the company and Ghana, the market it is here addressing. By creating a stark difference between itself and Ghana when it comes to economic identity, the narrative succeeds in creating a distal relationship between MTN and Ghana, a distal relationship between itself on the one hand and the Ghanaian consumer on the other.

If MTN constructs an identity that presents it as a state, in the sense of a brand that needs no adjustments to fulfil its role as an equal partner in one sense and the more accomplished partner in another, then Vodafone, the next focus of the analysis, constructs an identity of an entity that is fluid and progressive. The following extracts from the data will be used to demonstrate how this dynamic identity is constructed in the narrative.

a. We are the second ranked operator in mobile with a huge potential to take over the market.

b. As a corporate body, we value our customers and constantly build key relationships with the private sector and government.

In extract (a), two phrases stand out as evidence of the fluid and progressive identity that the company constructs for itself through this narrative. 'Second ranked' is an admission of the view that the company still needs growth that will ensure that it rises to the highest position within the Ghanaian market. The second phrase, 'a huge potential' also expresses this identity of the progressive entity which is yet to peak in terms of its development. In extract (b), the same image is expressed in 'constantly build key relationships'. A company that is young and growing and yet to peak is one that many Ghanaians are easily likely to associate with. This is because this narrative place the identity of the company within the larger 
developmental narrative that constructs Ghana's identity as a country that is underdeveloped and yet full of potential and as such needs growth, progress and development. The construction of this identity in the narrative therefore creates a proximal relationship between Vodafone and Ghanaians since the two share a dyadic identity and a common aspiration.

The argument that the company, through the narrative, constructs an identity that shrinks the social distance between itself and its target market is further reinforced through an anthropomorphism that gives human agency to the company. The following extracts from the data will help make this point clearer.

a. We are the second ranked operator in mobile telephony...

b. As a corporate body, we value our customers...

By using the inclusive personal pronoun, we in this narrative, the company is no longer thought of as a passive and non-human entity, but one that is alive. The most important human attribute that the company acquires because of the anthropomorphism is that of speech. This allowed the company in the narrative to directly address the audience of the narrative in the first person. This ability to directly address the audience through speech creates an important social conduit that allows the company to relate to the individual at a personal level. It is this ability to relate at the personal level between the company and the individual, it is argued, that closes the social distance between the company and its target market.

A ubiquitous self is part of the corporate identity that is constructed by Vodafone through its narrative. This ubiquity is not in the sense of spatial ubiquity which is attained by means of a narrative that portrays the company as existing within every geographic space within Ghana; thereby highlighting the width and breadth of its network coverage but is rather constructed by a focus on the variety of telecommunications services the company provides. The narrative points out that the company is 'the only total communications solutions provider - mobile, fixed lines, internet, 
Ayaawan, A. E./ Corporate identity on the Web

voice and data'. This strategy used in constructing a ubiquitous identity helps the company draw attention to the products that it wants to market to its target customers so that a strong association is formed, in the minds of the audience, between the company and the products that it sells. Also, by highlighting the variety of the services and products that it has, the company succeeds in constructing a brand that is inclusive in the sense that it places itself in a position that ensures that it takes care of the varied needs of its customers. And perhaps most importantly, the image of the company as the provider of solutions to all sorts of telecommunications problems is vital in the sense that it serves as a powerful counter-balance to the company's identity as a progressive and growing entity. This counter-balancing allows the company to still maintain a credible identity (the mature identity) and at the same time not antagonise its market by constructing a narrative that suggests a vertical relationship between the company and its market.

Some of the observations that have been made about the strategies as well as the corporate identities of MTN and Vodafone hold true for both Airtel and Tigo (for instance, the glocalisation of corporate identity). But as would be expected of any instantiation of discourse that is promotional and situated within a competitive environment, the discovery of enacted identities that are unique should be viewed as a matter of course. In this light, the analysis proceeds to point out the identities that are unique to these two other companies and the strategies used in the construction of those corporate identities.

The point has been made within this discussion that the telecommunication companies employ language that deliberately masks the real purpose of their existence - money/profit; and have instead adopted an interdiscursive strategy that allows them to define themselves as partners in development. This is not the case with Tigo and to a varying degree, Airtel. The following phrases extracted from the data from Tigo's website helps in highlighting this difference in identity and the strategy employed to construct that identity. 
Ayaawan, A. E./ Legon Journal of the Humanities 29.1 (2018)

Emerging market, affordable, 30 million customers, business model, affordable rates, affordability, subscribers, 180 million people

These phrases clearly point to the construction of a corporate identity that foregrounds profit which is more in tune with the capitalist ideology that births corporate entities including telecommunication companies in general. The discourse makes no attempt to hide the 'for-profit identity' of the company and as such situates the company's own identity within the notion of the business model. This then allows the company to define the individuals and organisations for which it provides service to as customers/subscribers and the entire socio-cultural as well as economic context within which it exists and operates as an emerging market - a place for maximising profit. This explains why the company's vision is to have ' 180 million people' which will ensure that the company becomes 'the most consumed digital service provider in urban areas' For Airtel also, the focus is on enacting an identity that projects it as a commodity for consumption by 'customers, top talents, businesses'.

From the analysis in the preceding paragraph, it is clear that the 'for-profit identity' constructed by these two companies, as well as the strategies used in constructing that identity, is informed not by the ideology which underpins the discourse of development and the First/Third Worlds schema. Rather, it is shaped by the capitalist ideology which emphasises profit maximisation. The capitalist ideology which underpins the discursive construction of corporate identity within the discourse gives rise to two seemingly opposed hegemonic situations. When the two telecommunication companies present themselves as products designed to conform to the needs of the customer, a hegemony in which the identity of the company is defined by the customer arises. In this situation, the customer is in the position of power. This is because the customer effectively is the individual defining the identity of the company in a way that aligns the company's identity with that of the customer. On the other hand, and at another level, the companies have presented themselves as the providers of services, the owners of services 
that the customers desire to consume. The companies in this case present themselves as possessing something that the consumer desires and can only have at the dictates of the company. In this case, the power that establishes the vertical relationship is in the hands of the company. This gives rise to a hegemony, which is the reverse of the hegemony established when the companies enact an identity in which they are a product. This state results in an oscillation of power. The oscillation of power has therefore resulted in the creation of a hegemonic paradox where both actors within the narrative assume dominant and dominated status.

The focus of this discussion has been to examine the discursive construction of corporate identity within the About Us section on the websites of the four leading telecommunication companies in Ghana. The specific concerns have been to (a) reveal what corporate identities are constructed (b) examine the strategies used in constructing the identities and (c) investigate the ways in which ideology, power and hegemony inform both the identities constructed and the discursive strategies used in constructing these identities. The analysis has established that the corporate identity constructed is a glocalised identity. This glocalised identity ensures that the companies are associated with the credibility provided by the West and yet retain an identity that allows them to be integrated into the social structure of its immediate context - Ghana. The analysis has also established that MTN and Vodafone enact a human-centred identity that masks their corporate mandates and instead, enacts a development-partner identity for them. Tigo and Airtel maintain a 'for-profit identity' instead. In terms of the discursive strategies used in constructing identity, the analysis has further revealed that the inverted pyramid structure of the narratives, interdiscursivity, binarity, as well as metaphor, are the strategies deployed by the four major telecommunication companies in Ghana. Additionally, the discussion has argued that Eurocentric ideology and the ideology of capitalism underpin the identities constructed as well as the discursive strategies used. These ideologies allow the fluidity of power - power in the discourse oscillating between the companies and the consumers of the discourse (Customers) - which results in 
a hegemonic paradox.

\section{Conclusion}

This paper has, through the framework of CDA, examined the construction of corporate identity on the web. The specific objectives of the paper were to examine how the four (4) leading telecommunications companies in Ghana construct their corporate identities through the About Us section hosted within the websites of these companies, what corporate identities these companies construct as well as how ideology, power and hegemony influence the identities constructed through the About Us section. Interdiscursivity, binarity and metaphor were found to be the leading strategies for the construction of corporate identity. In terms the kinds of identities enacted, the study revealed that the companies constructed a glocal identity and that this glocal identity was informed by a First World - Third World schema. It was also revealed that although there were points of convergence with regard to the kinds of identities constructed by the companies, the companies' identities were largely heterogeneous. 


\section{References}

Balmer, J. M. (2001). Corporate identity, corporate branding and corporate marketing: Seeing through the fog. European Journal of Marketing, $35(3 / 4), 248-291$.

Bhatia, V. K. (2010). Interdiscursivity in professional communication. Discourse and Communication, 4(1), 32-50.

Billig, M. (2003). Critical discourse analysis and the rhetoric of critique. In G. Weiss \& R. Wodak (Eds.), Critical discourse analysis: Theory and Interdisplinarity (pp. 35-46). Hampshire: Palgrave Macmillan.

Burke, P. J., \& Stets, J. E. (2009). Identity theory. Oxford: Oxford University Press.

Coupland, C. (2003). Corporate identities on the web:An exercise in the construction and deployment of morality. Working Paper. Center for Corporate Social Responsibility, Nottingham University Business School.

Dijk, T. A. (2008). Critical discourse studies: A sociocognitive approach. In R. Wodak \& M. Meyer (Eds.), Methods of critical discourse analysis (pp. 62-86). London: Sage.

Evangelisti-Allori, P., \& Garzone, G. (2010). Identities, discourse and genres in corporate communication: An introduction. In P. Evangelisti-Allori, \& G. Garzone (Eds.), Discourse, identities and genres in corporate communication (pp. 9-26). Bern: Peter Lang.

Hall, S. (1991). The local and global: Globalisation and ethnicity. In A. D. King (Ed.), Cultural, globalisation and the world system: Contemporary condition for the representation of identity (pp. 19-40). Binghamton: State University of New York Press.

Hyland, K. (1998). Exploring corporate rhetoric: Metadiscourse in the CEO's letter. The Journal of Business Communication, 35(2), 224-244.

Liu, M., \& Wu, D. (2015). Discursive construction of corporate identity on the web: A glocalisation perspective. Intercultural Communication Studies, 24(1), 50-65.

Moingeon, B., \& Ramanantsoa, B. (1997). Understanding corporate identity: The French school of thought. European Journal of Marketing, 31(5/6), 383-395.

Park, H., \& Reber, B. H. (2008). Relationship building and the use of web sites: How Fortune 500 corporations use their Web sites to uild relationships. Public Relations Review, 34(4), 409-411.

Ruelle, O., \& Peverelli, P. (2016). The discursive construction of identity through interaction on social. Chinese Journal of Communication, 10(1), 12-37.

Simon, R. (1982). Gramsci's political thought. London: Lawrence and Wishart.

Stoddart, M. C. (2007). Ideology, hegemony, discourse: A crtical review of theories of knowledge and power. Social Thought and Research, 28, $192-225$. 
Ayaawan, A. E./ Legon Journal of the Humanities 29.1 (2018)

Stuart, H. (1999). Towards a definitive model of corporate identity management process. Corporate Communication: An International Journal, 4(4), 200-207.

Thomson, E. A., White, P. R., \& Kitley, P. (2008). "Objectivity" and "hard news" reporting across. Journalism Studies, 9(2), 212-228.

Wodak, R. (1996). Disorders of discourse. London: Longman.

Wodak, R., \& Meyer, M. (2008). Critical discourse analysis: History, agenda, theory and methodology. In R. Wodak \& M. Meyer (Eds.), Methods of critical discourse analysis (pp. 1-32). London: Sage. 